\title{
Chlamydia trachomatis responds to heat shock, penicillin induced persistence, and IFN-gamma persistence by altering levels of the extracytoplasmic stress response protease HtrA Wilhelmina M Huston*1, Christina Theodoropoulos ${ }^{2}$, Sarah A Mathews ${ }^{1}$ and Peter Timms ${ }^{1}$
}

\author{
Address: ${ }^{1}$ Institute of Health and Biomedical Innovation, 60 Musk Ave, Queensland University of Technology, Kelvin Grove, QLD, 4059, Australia \\ and ${ }^{2}$ Analytical and Electron Microscopy Facility, Queensland University of Technology, Brisbane, QLD, 4001, Australia \\ Email: Wilhelmina M Huston* -w.huston@qut.edu.au; Christina Theodoropoulos - c.theodoropoulos@qut.edu.au; \\ Sarah A Mathews - s.mathews@qut.edu.au; PeterTimms - p.timms@qut.edu.au \\ * Corresponding author
}

Published: 6 November 2008

BMC Microbiology 2008, 8:190 doi:10.1 I86/147I-2180-8-190

This article is available from: http://www.biomedcentral.com/147I-2180/8/190

(C) 2008 Huston et al; licensee BioMed Central Ltd.

This is an Open Access article distributed under the terms of the Creative Commons Attribution License (http://creativecommons.org/licenses/by/2.0), which permits unrestricted use, distribution, and reproduction in any medium, provided the original work is properly cited.
Received: 13 August 2008

Accepted: 6 November 2008

\begin{abstract}
Background: Chlamydia trachomatis, an obligate intracellular human pathogen, is the most prevalent bacterial sexually transmitted infection worldwide and a leading cause of preventable blindness. HtrA is a virulence and stress response periplasmic serine protease and molecular chaperone found in many bacteria. Recombinant purified C. trachomatis HtrA has been previously shown to have both activities. This investigation examined the physiological role of Chlamydia trachomatis HtrA.
\end{abstract}

Results: The Chlamydia trachomatis htrA gene complemented the lethal high temperature phenotype of Escherichia coli htrA $\left(>42^{\circ} \mathrm{C}\right)$. HtrA levels were detected to increase by western blot and immunofluorescence during Chlamydia heat shock experiments. Confocal laser scanning microscopy revealed a likely periplasmic localisation of $\mathrm{HtrA}$. During penicillin induced persistence of Chlamydia trachomatis, HtrA levels (as a ratio of LPS) were initially less than control acute cultures ( $20 \mathrm{~h}$ post infection) but increased to more than acute cultures at $44 \mathrm{~h}$ post infection. This was unlike IFN- $\gamma$ persistence where lower levels of HtrA were observed, suggesting Chlamydia trachomatis IFN- $\gamma$ persistence does not involve a broad stress response.

Conclusion: The heterologous heat shock protection for Escherichia coli, and increased HtrA during cell wall disruption via penicillin and heat shock, indicates an important role for $\mathrm{HtrA}$ during high protein stress conditions for Chlamydia trachomatis.

\section{Background}

HtrA is a highly conserved serine protease and chaperone found in both eukaryote and prokaryote organisms (reviewed [1]. Escherichia (E.) coli htrA was identified as essential for growth at temperatures higher than $42^{\circ} \mathrm{C}$ (high temperature requirement) [2], and as the locus required for degradation of misfolded proteins (hence it is also referred to as DegP) [3]. HtrA has since been reported to be a periplasmic protease and chaperone during E. coli extracytoplasmic stress response, with a structural temperature switch to mediate between these two activities [4-6]. HtrA has important functions for virulence and stress 
resistance in a variety of bacteria (reviewed [7]). Recently we characterised purified recombinant HtrA from Chlamydia (C.) trachomatis L2, demonstrating that it had biochemical features typical of a HtrA protease, and critically, that it was capable of both protease and chaperone activities at physiologically relevant temperatures [8]. The protease activity was temperature activated $\left(\geq 34^{\circ} \mathrm{C}\right)$ and specific for unfolded proteins. However, the physiological function of HtrA during the developmental cycle of Chlamydia is currently unknown.

Chlamydia is an obligate intracellular bacterial pathogen, which is unable to be genetically manipulated, making traditional approaches such as gene deletion studies currently impossible. The bacterium undergoes a unique biphasic developmental cycle consisting of small $(0.2$ $\mu \mathrm{m})$ extracellular, metabolically in-active, infectious particles called elementary bodies (EBs) and larger $(0.8 \mu \mathrm{m}-$ $1.0 \mu \mathrm{m})$ intracellular, metabolically active particles termed reticulate bodies (RBs) (approximately 12-36 h post infection (PI) for C. trachomatis L2) (reviewed [9]). The RBs asynchronously reorganise back to EBs to enable continued infections. htrA expression may occur throughout much of the developmental cycle of $C$. trachomatis, as transcripts for the gene were detected from $8 \mathrm{~h}$ to $40 \mathrm{~h} \mathrm{PI}$, with much higher expression levels occurring later in development [10].

Chlamydia can also enter a persistent phase of development whereby the RBs morphologically and metabolically adapt to remain indefinitely within the host cells, often in response to nutrient deprivation or other stress conditions [11-13]. Persistence induced by the presence of the cytokine IFN- $\gamma$, thought to correlate with in vivo chronic infections, has been widely used in laboratory studies to investigate the molecular basis of persistence [13]. Depletion of host cell pools of tryptophan via IFN- $\gamma$ induction of indoleamine-2,3-dioxygenase, the first enzyme in the catabolism of this amino acid has been characterised as the mechanism leading to persistence of C. trachomatis [14]. The IFN- $\gamma$ persistent Chlamydia typically are larger morphologically altered RBs, with fewer cells present in each inclusion and do not produce EBs [13]. The effect of IFN- $\gamma$ treatment on C. trachomatis transcriptome was analysed by Belland and coworkers [15], who reported that HtrA transcript levels during IFN- $\gamma$ persistence were approximately 2 fold less than acute conditions at $24 \mathrm{~h}$ PI and were present at similar levels to acute cultures at $48 \mathrm{~h}$ PI. The gene for the major outer membrane protein (ompA gene, MOMP) transcript was also reduced during IFN- $\gamma$ persistence [15]. MOMP and LPS proteins were reported to decrease during IFN- $\gamma$ persistent cultures of $C$. trachomatis although the decrease was most noticeable at time points beyond the scope of this investigation $[13,14]$. In contrast, HtrA protein levels increased during IFN- $\gamma$ persistent infection models with C. pneumoniae [16]. Furthermore, a key role of HtrA during heat stress was also suggested by the detection of 9.6 fold increased levels of HtrA during a proteomic analysis of heat shock response in C. pneumoniae [16]. Penicillin is also known to induce persistence of $C$. trachomatis by inhibition of binary fission of RBs from approximately 12 hours into development, although chromosome and plasmid replication continues, and enlarged RBs are formed in large inclusions [17-19].

In the absence of a transformation system, genomic and proteomic approaches have been used to probe the function of many genes throughout the developmental cycle and persistence cultures of Chlamydia. In the present study, we have analysed C. trachomatis L2 HtrA during development, persistence, and heat shock conditions using polyclonal sera generated against purified recombinant HtrA to test the protein levels by western blotting and immunocytochemistry. The ability of the C. trachomatis $\mathrm{L} 2 \mathrm{htrA}$ to complement the heat sensitive phenotype of E. coli htrA- was also demonstrated.

\section{Results \\ HtrA is highly conserved between Chlamydia species and is homologous to E. coli HtrA}

There is considerable knowledge of the key residues and domains involved in the protease and chaperone activities for HtrA from E. coli (EcHtrA), and high conservation of these residues in other bacterial HtrA homologs has been reported [20-22]. HtrA is highly conserved throughout the Chlamydia species (sp.) as multiple sequence alignment demonstrated $64 \%$ identity and $17 \%$ similarity of the amino acid sequences (Fig. 1). The high homology of HtrA between the Chlamydia sp. is supported by the ability of the polyclonal sera generated to recombinant $C$. trachomatis L2 HtrA (this study, CtHtrA) to detect $C$. pneumoniae AR39 HtrA by immunofluorescence (Fig. 1B). The three essential residues for serine protease activity (Fig. 1A), and the two putative C-terminal PDZ domains are conserved in all of the Chlamydia HtrA homologs from the available genomes. PDZ domains function in protein-protein interaction and protein binding in a range of different proteins [23]. PDZ1 sequence is highly conserved between chlamydial HtrAs, functions in E. coli HtrA for coordinating substrate binding and access to the active site, including by binding of the carboxyl terminal of the protein substrates, PDZ2 is known to function in protein interaction within the E. coli HtrA hexameric structure $[23,24]$. The homology between the ancestoral relative Parachlamydiaceae HtrA sequences and Chlamydia was found to be not a lot greater than the homology to E. coli HtrA, suggesting whilst key features remain conserved, HtrA has evolved along with the Chlamydia genomes to suit the intracellular niche. The predicted cellular location of HtrA is within the 


\begin{tabular}{|c|c|c|c|}
\hline $\mathrm{N}$ & Serine protease domain & PDZ 1 & PDZ 2 \\
\hline CtHtrA $\bar{\Gamma}$ & $\begin{array}{lll}\mathrm{H}_{146} & \mathrm{D}_{179} & \mathbf{S}_{247}\end{array}$ & $\mathbf{S}_{268}$ & $\mathbf{E}_{497}$ \\
\hline Chlamydia sp. & $70.7 \%$ & $83.0 \%$ & $45.9 \%$ \\
\hline Parachlamydia & $47.0 \%$ & $53.0 \%$ & $27.0 \%$ \\
\hline E. coli & $40.3 \%$ & $48.8 \%$ & $25.0 \%$ \\
\hline
\end{tabular}

\section{D-GYVVTNHAVVED 173AKIVGLDPKTDLAVI 236QTDAAINP GNSGGP IININC DRGYVVTNNHVVDNA ARMVGRDPRSDIALI QTDAAINRGNSGGALVNLNC}

$\mathrm{B}$

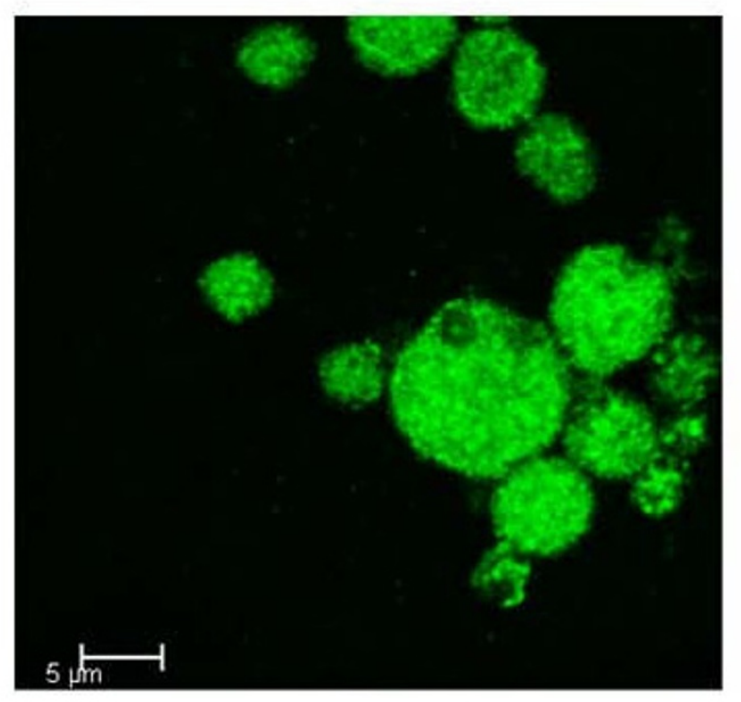

Figure I

HtrA conservation between Chlamydia and $E$. coli shows likely functional redundancy between bacterial species. (A) Schematic of the HtrA protein from C. trachomatis is shown. The predicted $\mathrm{N}$-terminal secretion signal sequence (shaded) and signal protease cleavage site (A25-S26), serine protease domain and two C-terminal PDZ domains are shown. The percentage of conservation of amino acid sequences (identical residues) for each of these regions between Chlamydia species, between all Chlamydia and Parachlamydia, and between E. coli HtrA and C. trachomatis HtrA (E. coli) are indicated below. An alignment of the residues surrounding the three essential residues for serine protease catalytic triad (HI46, DI79, S247; diamonds) from C. trachomatis L2 and E. coli HtrA is shown. (B) Immunohistochemistry using HtrA polyclonal sera with HEp-2 cells infected with $C$. pneumoniae AR39 at $72 \mathrm{~h} \mathrm{PI}$. C. pneumoniae AR39 infections were centrifuged for $30 \mathrm{mins}$ at $2000 \mathrm{rpm}$ and media changed at $2 \mathrm{~h} \mathrm{PI}$ to media with I mg/ml cyclohexamide. Cells were fixed and stained as described in Methods.

periplasm for all Chlamydia sp, as determined using PSORT andSignalP $[25,26]$. This suggests that Chlamydia HtrA has a similar physiological function to the homologs in other bacteria for maintenance of extracytoplasmic protein quality, by both protease and chaperone activities.

\section{C. trachomatis htrA can complement the lethal high temperature phenotype of $E$. coli htrA-}

The increased levels of HtrA during C. pneumoniae heat shock [16], and the essential role for E. coli htrA during growth at temperatures higher than $42^{\circ} \mathrm{C}$ [2], have led us to test the ability of Chlamydia HtrA to complement the heat sensitive phenotype of $h t r A^{-} E$. coli. A htrA- mutant was generated in E. coli MG1655 for the purposes of this investigation using the $\lambda$ red recombinase method as 
described by Datensko and Wanner [27]. The htrA- strain was verified by PCR analysis using primers to the Kan cassette and to the chromosome flanking the htrA gene (primer sequences shown in Methods, data not shown), the strain showed the expected phenotype of lack of growth at $44^{\circ} \mathrm{C}$ when tested on LB agar plates, whereas the wild-type (MG1655) was able to grow (data not shown). The ability of the E. coli htrA (echtrA) and C. trachomatis htrA (cthtrA) genes supplied on the low copy number vector pACYC184 (constructed as described in Methods) to complement the heat sensitive phenotype of the E. coli htrA- mutant was tested. When E. coli htrA- was complemented with either E. coli or C. trachomatis htrA ( $h t r A^{-}$pACYCechtrA and $h t r A^{-}$pACYCcthtrA respectively) growth was restored at $44^{\circ} \mathrm{C}$. The E. coli htrA- strain harbouring only pACYC184 ( $h$ trA- $\mathrm{pACYC184)}$ was unable to grow at $44^{\circ} \mathrm{C}$ on LB agar plates (data not shown). Thus, both the E. coli htrA and C. trachomatis htrA genes are able to complement the heat stress phenotype of E. coli htrA-.

During the initial stages of this investigation the C. trachomatis htrA was supplied on the higher copy number vector pBR322 which proved toxic to E. coli at $30^{\circ} \mathrm{C}$, and was unable to complement the heat sensitive phenotype (data not shown). This finding is consistent with previous reports of a similar copy number dependent toxicity of the E. coli htrA gene during complementation studies [2]. In order to ensure that no toxicity occurred with either C. trachomatis or E. coli htrA genes, the strains were further tested by determining growth curves at $30^{\circ} \mathrm{C}$ and $44^{\circ} \mathrm{C}$ on LB broth. The presence of either pACYCechtrA or pACYCcthtrA did not alter the growth of $h t r A^{-}$E. coli at $30^{\circ} \mathrm{C}$ aerobically on LB media (Fig. 2A), similarly no effect of the complementation plasmids was observed for the growth of wild-type MG1655 (data not shown). The complementation plasmids were not able to completely restore the growth of $h t r A^{-}$to that of wild-type when grown aerobically at $44^{\circ} \mathrm{C}$ (LB media) (Fig. 2B), however the strains were able to grow under these conditions where $h t r A^{-}$is lethal, demonstrating that on both liquid media and agar plates the C. trachomatis htrA- gene was able to complement the lethal high temperature phenotype of $E$. coli htrA-.

In order to confirm that the complementation was due to the presence of $C$. trachomatis HtrA protein (CtHtrA), western blots were conducted on the total soluble extracts from the E. coli strains using the polyclonal sera generated for this investigation. The CtHtrA protein was present in the MG1655 pAYCYcthtrA (lanes 2 and 6) and htrA- pAYCYcthtrA (lanes 5 and 8) strains grown at both $30^{\circ} \mathrm{C}$ and $44^{\circ} \mathrm{C}$ (Fig. 2C). The CtHtrA, protein which is predicted to be $50.6 \mathrm{kDa}$, appears as a doublet on the western blot at approximately $50 \mathrm{kDa}$, which is likely due to the mature and immature forms of the protein where the signal sequence is not yet cleaved. The Figure also shows a western blot with C. trachomatis uninfected and infected HEp2 cell extracts to demonstrate the specificity of the sera to a band at the expected size for CtHtrA (Fig. 2C, lanes 10 and 11).

\section{HtrA is present at higher levels in Chlamydia trachomatis L2 during heat stress}

The increased levels of the HtrA from C. pneumoniae heat stress cultures [16], and the ability of C. trachomatis HtrA to complement the heat sensitive phenotype of E. coli $h t r A^{-}$both suggest a critical role for HtrA in the Chlamydia heat stress response. The expression of HtrA from C. trachomatis during heat stress was tested using using C. trachomatis L2 infected HEp-2 monolayers at $20 \mathrm{~h}$ PI (post infection) which represents the mid-phase of Chlamydia development, when RBs are actively dividing. Cultures at $20 \mathrm{~h}$ PI were shifted to $42^{\circ} \mathrm{C}$ for $3 \mathrm{~h}$ and total cellular extract was immediately harvested; controls included uninfected HEp-2 cells and cultures which were not heat stressed. The cultures were examined by transmission electron microscopy (TEM) to determine the affect of heat stress on the morphology of the Chlamydia (Fig. 3A-B). The heat stressed cultures showed clear morphological alterations compared to untreated (acute) cultures, including: reduced numbers of RBs within the inclusion, larger RBs with condensation of electron opaque material within the RBs and excess membranous-like material within the inclusion.

Total cellular extracts (loaded to equivalent protein amounts from total culture extracts) from the acute and heat stressed cultures were analysed by western blots for HtrA (Fig. 3C). Western blots for MOMP were conducted on the same samples to allow comparative analysis using densiotometry quanitification of band intensities in each sample (Fig. 3C). The localisation and expression of MOMP and HtrA was examined by indirect immunofluorescence microscopy (using the confocal laser scanning microscope, CLSM), where increased levels of HtrA immunofluorescence was detected during heat stress compared to acute conditions (Fig.4A-B). These results showed that MOMP protein levels decrease during heat stress (Fig. 4C), whereas the HtrA protein intensity showed a marked increase during heat stress when compared to acute conditions.

A similar trend was observed when HtrA immunofluorescence was compared to lipopolysaccharide (LPS) immunofluorescence during co-labelling experiments. LPS is significantly reduced during heat stress conditions (as shown in Fig. 5), whereas HtrA levels showed a marked increase (2.01 fold relative to LPS). These observations all support a key role for HtrA in the heat stress response by C. trachomatis. 

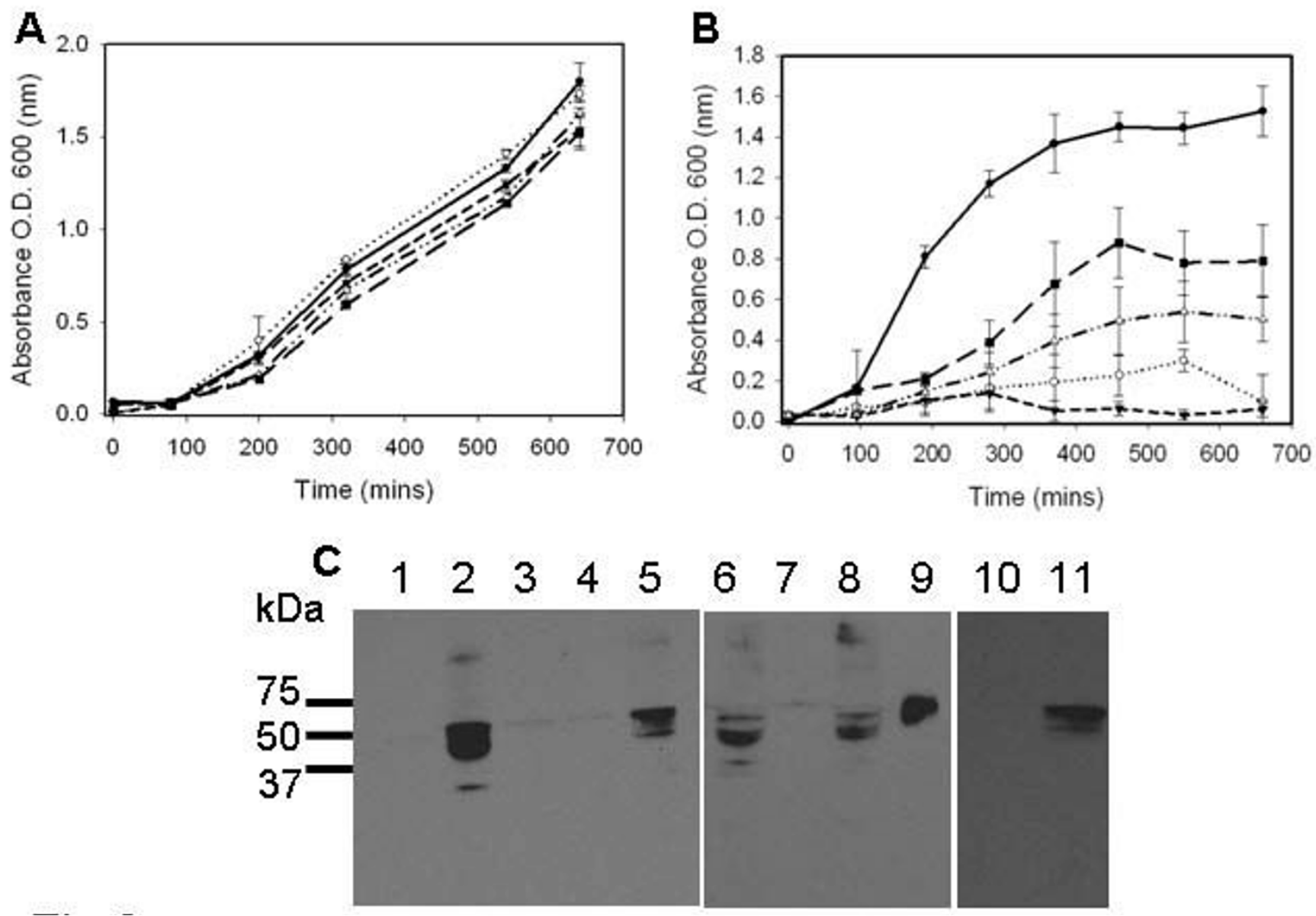

Figure 2

Growth curve analysis of the complementation of $E$. coli htrA-temperature sensitive phenotype by $C$. trachomatis htrA. (A. B.) Growth of E. coli strains at $30^{\circ} \mathrm{C}$ (A) and $44^{\circ} \mathrm{C}$ (B). Samples are: Solid line; MG I 655: wild-type E. coli; dashed line: $h t r A-$, dotted line: $h t r A-p A C Y C I 84$, dashed and dotted line; htrA-pACYCEcHtrA, large dashed line, htrA-pACYCCTHtrA. Triplicate cultures were conducted for each experiment, with standard deviations indicated by the error bars. (C) Western blot of the total E. coli extracts for CtHtrA protein. Samples are: (I-8: 30 ${ }^{\circ} \mathrm{C}$ ) I: E. coli MG I655, 2: E. coli MGI655 pACYCcthtrA, 3: E. coli htrA-pACYCI84, 4: E. coli htrA-pACYCechtrA, 5: E. coli htrA-pACYCcthtrA, (6-9 44 $\left.{ }^{\circ} \mathrm{C}\right)$ 6: E. coli MGI655 pACYCcthtrA, 7: E. coli htrA-pACYCechtrA, 8: E. coli htrA-pACYCcthtrA, 9: purified recombinant HtrA protein. Chlamydia culture samples are included; 10. total extract HEp-2 cells, I I. total extract HEp-2 C. trachomatis L2 infected (20 h PI).

\section{HtrA is likely to function during penicillin induced persistence of $\mathbf{C}$. trachomatis}

Analysis of the HtrA cellular localisation under acute conditions using immunocytochemistry and confocal microscopy showed that the protein is located solely around the periphery of each reticulate body at $20 \mathrm{~h} \mathrm{PI}$; there was no immunofluorescence detected within the cytoplasmic space of the bacteria (Fig. 6A, Additional file 1). There are 6 inclusion vacuoles with numerous RBs within each inclusion visible in Fig 6A, each RB visible shows HtrA staining is only present around the periphery of the cell which supports extracytoplasmic location of HtrA, which could be periplasmic considering the in silico predictions. Similarly when closely examining every reticulate body within an inclusion vacuole HtrA staining was only visible around the periphery (Additional file 1; video of a series of $\mathrm{Z}$ sections). The labelling of the $44 \mathrm{~h}$ PI cultures with HtrA was consistent with the observations for $20 \mathrm{~h}$ PI with HtrA immunofluorescence also associated with the periphery of individual RBs. Additionally, increased intensity of HtrA immunofluorescence was associated with smaller particles corresponding to the size of both intermediate bodies (RB mid-conversion to $\mathrm{EB}$ ) and EBs which would be expected to be present in the culture at 

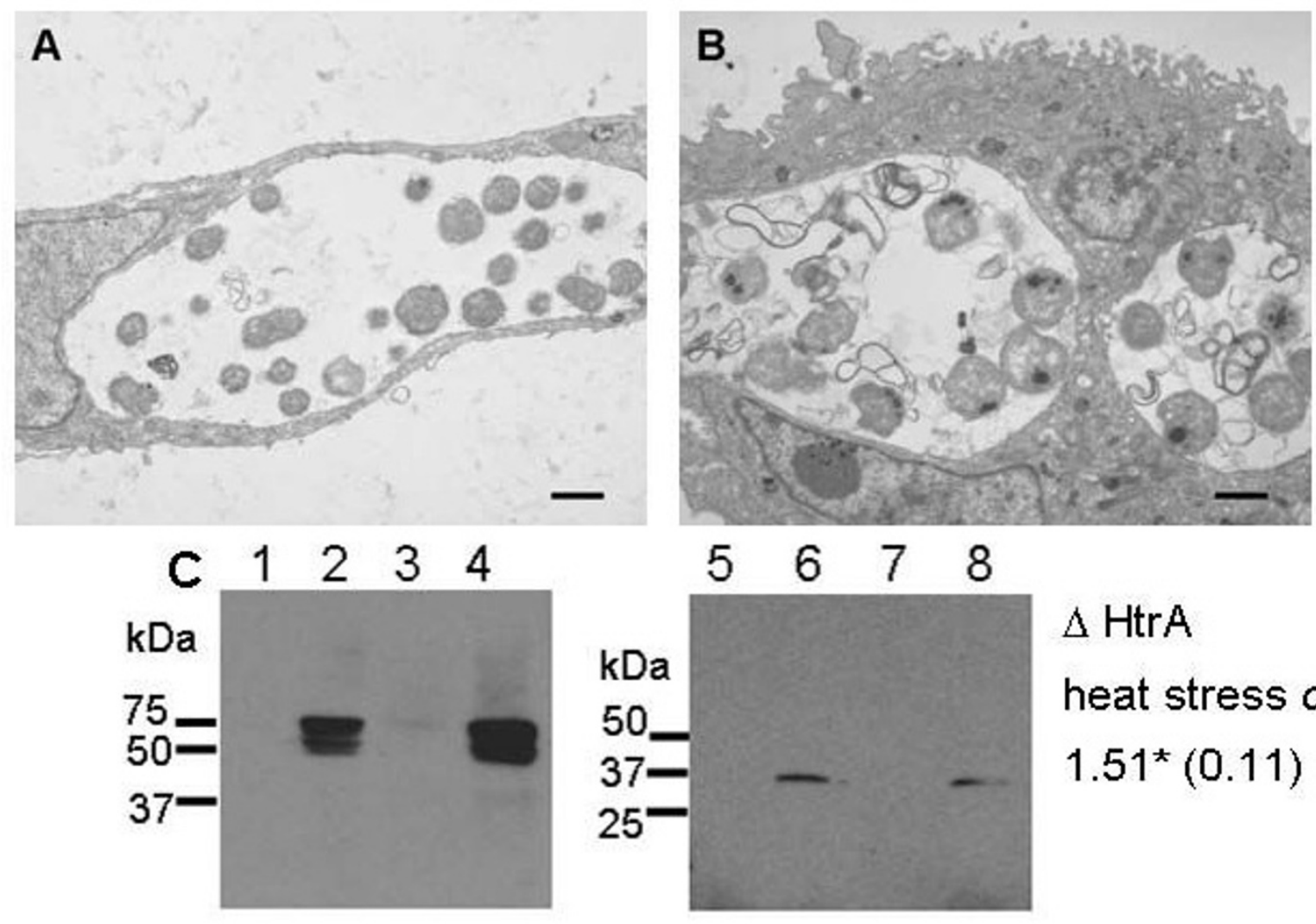

$\Delta \mathrm{HtrA}$

heat stress c.f. acute $1.51 *(0.11)$

\begin{abstract}
Figure 3
C. trachomatisL2 response to heat shock includes increased levels of the HtrA protein and significant morphological alterations. (A) Transmission electron micrographs (TEM) of a C. trachomatis L2 infected HEp-2 cell (acute infection) at $23 \mathrm{~h}$ PI. (B) TEM of a C. trachomatis L2 infected HEp-2 cell which was shifted to $42^{\circ} \mathrm{C}$ for $3 \mathrm{~h}$ at $20 \mathrm{~h} \mathrm{PI} \mathrm{(23} \mathrm{h} \mathrm{PI).} \mathrm{(C)} \mathrm{Western}$ blots for HtrA and MOMP against total cellular extracts from the acute and heat shock cultures. Samples are (HtrA polyclonal sera) I: uninfected HEp-2 cells acute conditions, 2: $C$. trachomatis L2 infected HEp-2 cells acute (23 h PI), 3: uninfected HEp-2 cells heat shocked for $3 \mathrm{~h}$ at $42^{\circ} \mathrm{C}$ at 20 hours post infection, 4: C. trachomatis L2 infected HEp-2 cells heat shocked for $3 \mathrm{~h}$ at $42^{\circ} \mathrm{C}$ at $20 \mathrm{~h} \mathrm{Pl}$; (MOMP monoclonal antibody) 5: uninfected HEp-2 cells acute conditions, 6: C. trachomatis L2 infected HEp-2 cells acute $(23 \mathrm{~h} \mathrm{PI}), 7$ : uninfected HEp-2 cells heat shocked for $3 \mathrm{~h}$ at $42^{\circ} \mathrm{C}$ at $20 \mathrm{~h} \mathrm{PI}, 8: \mathrm{C}$. trachomatis L2 infected HEp-2 cells heat shocked for $3 \mathrm{~h}$ at $42^{\circ} \mathrm{C}$ at $20 \mathrm{~h} \mathrm{Pl}$. The quantification of HtrA western blot band intensity was conducted using densiotometry, three separate experiments examined by western blot were used to quantify the difference in band intensities between acute and heat shock samples. The average of these three differences (heat shock:acute) is indicated to the right of the figure with the standard deviation indicated in parentheses.
\end{abstract}

this later stage of development (Fig. 6G). MOMP immunofluorescence was observed at $20 \mathrm{~h}$ PI and $44 \mathrm{~h}$ PI (Fig. $6 \mathrm{D}, \mathrm{J})$.

Immunocytochemistry and confocal microscopy of MOMP and HtrA revealed that both proteins were present during mid (20 h PI) and later (44 h PI) stages of penicillin persistence and resolved larger RBs contained within large inclusions (Fig. 6B, E, H, K) compared to the control acute cultures (Fig. 6A, D, G, J). This is consistent with previous reports of the Chlamydia trachomatis morphology during penicillin persistence $[13,17]$. HtrA and MOMP were also detected by western blot from the penicillin persistent cultures although less protein was detected than that observed for acute conditions (Fig. 7). The analysis of the persistent cultures by dual labelling immunocytochemistry for HtrA and LPS demonstrated that LPS is present during penicillin persistent cultures of C. trachomatis which is consistent with previous reports [28] (Fig. 9). Quantitative analysis of the fluorescence showed that HtrA was present at lower levels compared to acute cultures (as a ratio of LPS) at $20 \mathrm{~h} \mathrm{PI}$, but that higher levels of HtrA were present at $44 \mathrm{~h}$ PI (compared to acute cultures) (Table 1). 


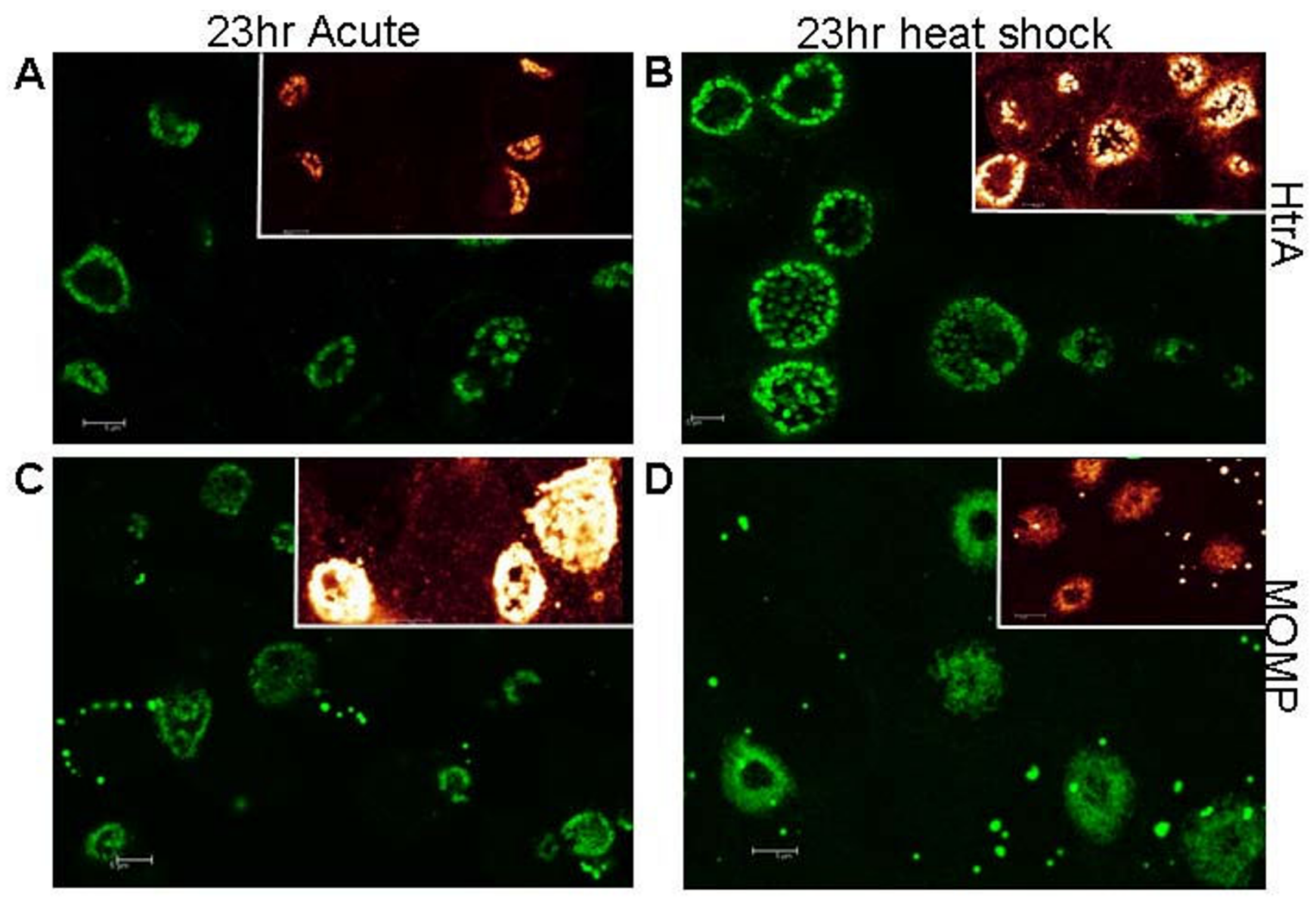

Figure 4

Immunofluorescence intensity of $\mathbf{H t r A}$ is much higher in heat shocked $C$. trachomatis. Immunocytochemistry on $C$. trachomatis L2 infected HEp-2 cells using antibodies to HtrA and MOMP. Immunofluorescence images collected using confocal microscopy with insert showing intensity differences (glow scale) from each experiment to demonstrate differences. Samples are (A) C. trachomatis L2 infected HEp-2 cells acute (23 h PI) (HtrA polyclonal sera). (B) C. trachomatis L2 infected HEp-2 cells heat shocked for $3 \mathrm{~h}$ at $42^{\circ} \mathrm{C}$ at $20 \mathrm{~h} \mathrm{PI}$ (HtrA polyclonal sera) $(23 \mathrm{~h} \mathrm{PI})$. (C) C. trachomatis L2 infected HEp-2 cells acute $(23 \mathrm{~h}$ $\mathrm{PI})\left(\mathrm{MOMP} \mathrm{mAb}\right.$ ). (D)C. trachomatis L2 infected HEp-2 cells heat shocked for $3 \mathrm{~h}$ at $42^{\circ} \mathrm{C}$ at $20 \mathrm{~h} \mathrm{PI}$ (MOMP mAb). The inserts in the top right show relative intensities and were recorded under identical microscope and laser settings, on the same day, to enable comparison of levels of fluorescence. Scale bars $(5 \mu \mathrm{M})$ are shown in the bottom left corner of each figure.

HtrA levels are lower during IFN- $\gamma$ persistence of $\mathbf{C}$. trachomatis when compared to acute conditions

HtrA, MOMP, and LPS were all detected by immunofluorescence at 20 and $44 \mathrm{~h}$ PI during IFN- $\gamma$ persistence cultures during this investigation (Fig. 6C, F, I, L). The HtrA and MOMP proteins were also detected by western blot (Fig. 7). The MOMP and HtrA bands, which are less intense then that in the acute cultures, appear to decrease in intensities from $20 \mathrm{~h}$ PI to $44 \mathrm{~h}$ PI in the western blots, consistent with the change in transcript levels previously reported $[15,18]$. The acute and IFN- $\gamma$ persistence cultures were examined by transmission electron microscopy (20 $\mathrm{h}$ PI) to determine if the RB morphology was comparable to that previously reported (Fig. 8), and the expected persistent morphology for RBs under these conditions was observed. HtrA immunofluorescence (as a ratio of LPS) from persistent cultures in the presence of IFN- $\gamma$ showed markedly reduced levels compared to acute culture controls at both $20 \mathrm{~h}$ and $44 \mathrm{~h}$ PI (Fig. 9G, H, I, P, Q, R and Table 1).

\section{Discussion}

HtrA is known to be an important stress response protease for many bacteria and has been shown to be critical for virulence in many bacteria, including intracellular pathogens Salmonella enterica and Legionella pneumophila $[29,30]$. There is considerable evidence from both microarray and proteomic studies that HtrA is expressed in Chlamydia. 

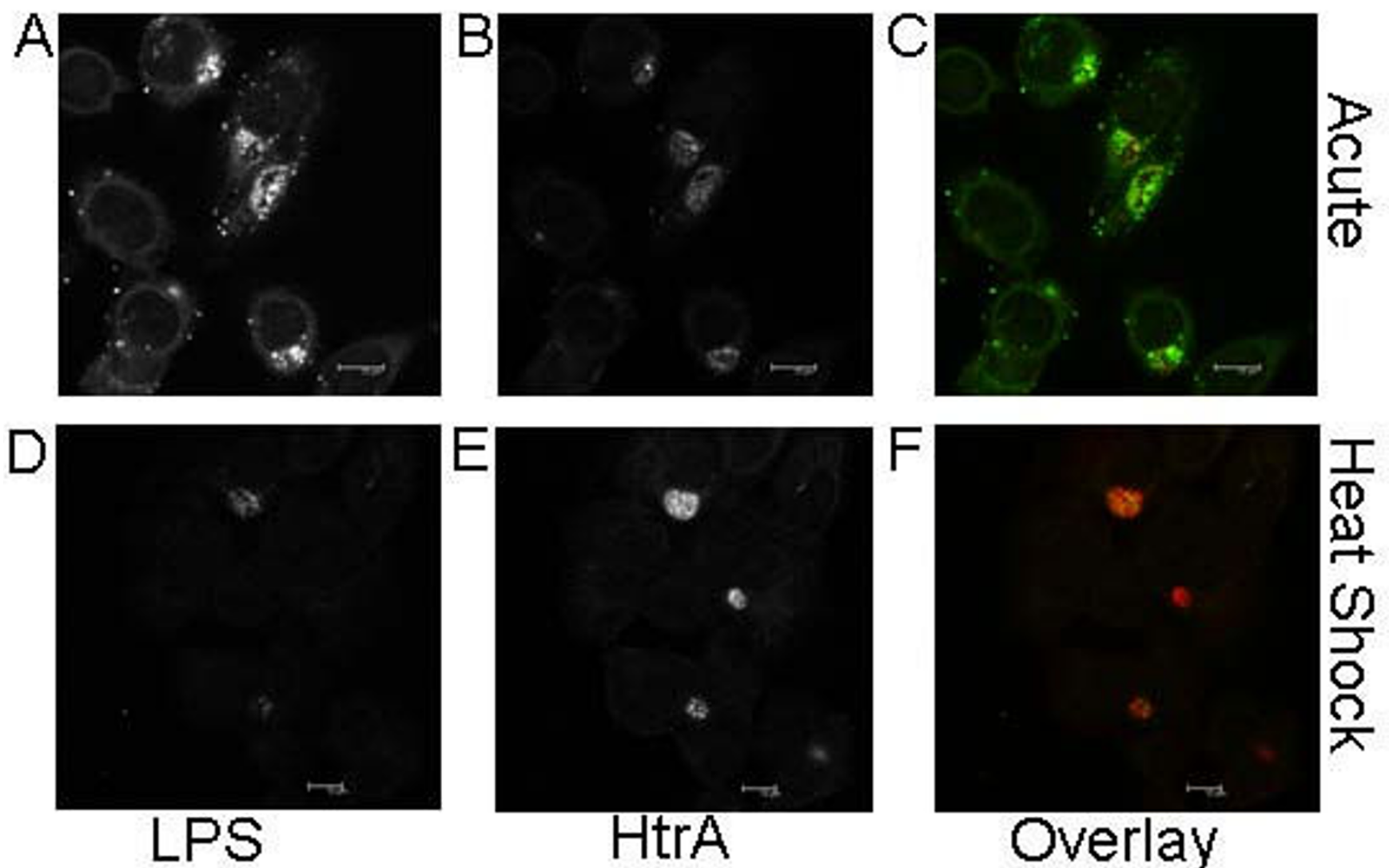

Overlay

\section{HtrA $^{\#}$ : Acute: $0.218(0.059)^{*}$ Heat shock: $2.14(0.73)$}

\section{Figure 5}

Quantification of HtrA and LPS by dual labelled immunoflourescence during acute and heat shocked culture of $C$. trachomatis L2. The Figure shows the immunoflourescence on co-labelled slides of LPS (A, D) HtrA (B, E) and overlays (C, F) during acute at $23 \mathrm{~h} \mathrm{PI}(\mathrm{A}-\mathrm{C})$ and heat shocked for $3 \mathrm{~h}$ at $42^{\circ} \mathrm{C}$ at $20 \mathrm{~h} \mathrm{PI}(23 \mathrm{~h} \mathrm{PI})$. Quantification of the HtrA immunoflourescence (as a ratio of LPS immunoflouresence) under each condition is indicated in the box below the Figure. \#The quantification was conducted using the Leica software suite on individually selected inclusions with a minimum of 20 separate inclusions included in each analysis, *standard deviation is indicated in parantheses. The immunolabelling was conducted as per Methods, under identical laser conditions on the same day between the acute and heat shocked slides to allow quantification of fluorescence. Note: The argon laser to detect the emission of the FITC in (480-550 nm) collection region is at I00\% laser power in these images due to the marked reduction in LPS present after heat shock, most other images presented in this paper with LPS-FITC labelling have been collected on $23 \%$ argon laser power. Scale bars ( $10 \mu \mathrm{M})$ are shown in the bottom right of each figure.

In the absence of a genetic manipulation system, a complementation approach was used to test the physiological function of C. trachomatis HtrA in a heterologous host $(E$. coli). E. coli HtrA protein (EcHtrA) and C. trachomatis HtrA protein (CtHtrA) are known to have differences in substrate specificity for their protease activities, although both have temperature activated protease activity, and are specific for unfolded proteins $[4,8]$. The findings reported here show that the C. trachomatis htrA was able to protect E. coli htrA-against its lethal high temperature phenotype. This suggests that the ability to chaperone and degrade unfolded proteins, regardless of specificity for residues at the site of peptide bond cleavage, is sufficient to protect against the damage caused by heat stress. Minor differences observed in complementation by echtrA and cthtrA (Fig. 2) could be attributed to; differences in substrate specificities of the enzymes, potential differences in the 'switch' to chaperone activity at higher temperatures as $E$. coli has been previously reported to act only as a chaperone at temperatures below $30^{\circ} \mathrm{C}$ (Speiss et al., 1999) although more recent studies suggest EcHtrA may have chaperone activity at higher temperatures (Skorko-Glonek 


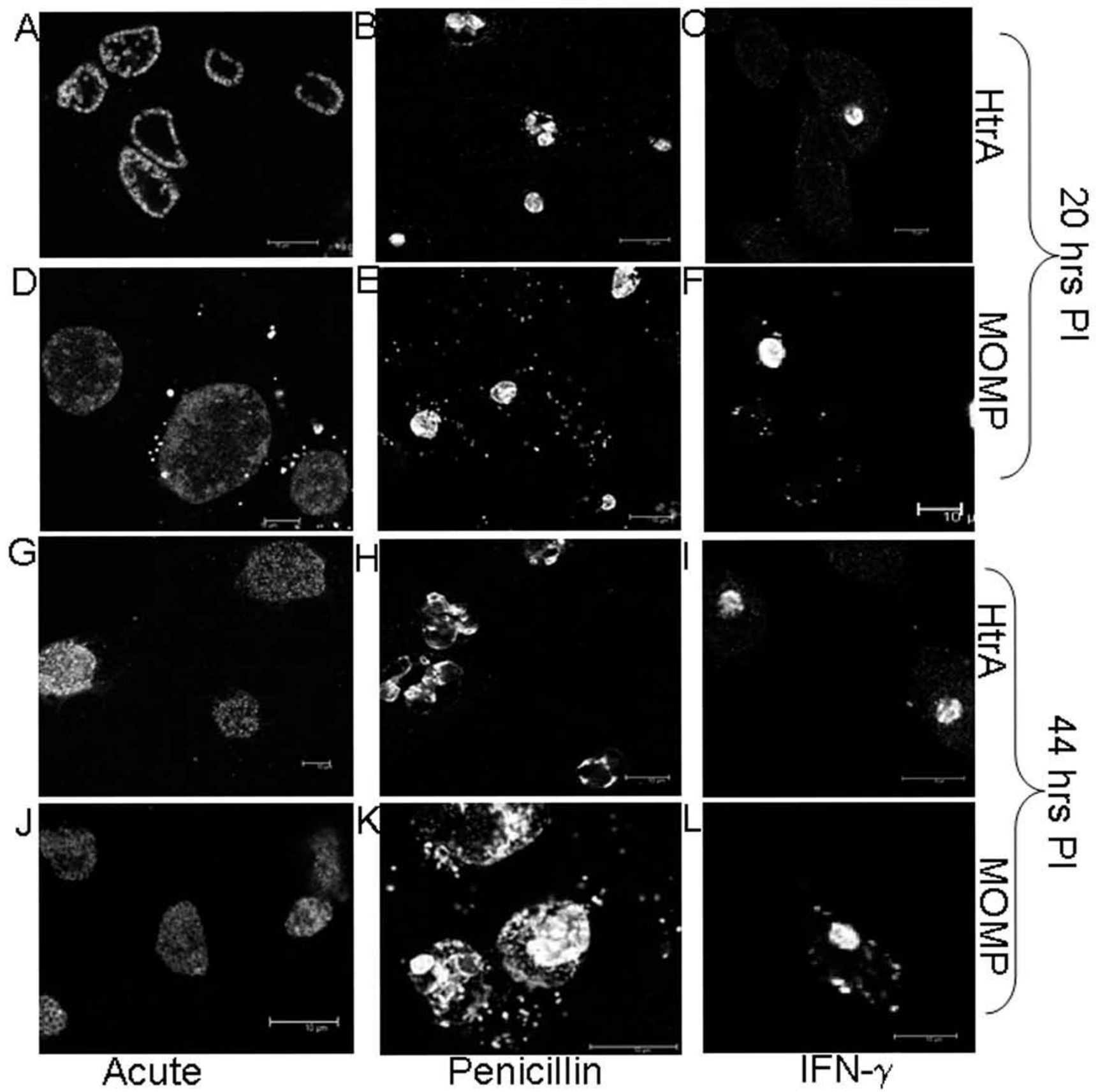

Figure 6

Immunofluorescence of HtrA and MOMP during acute, penicillin and IFN- $\gamma$ persistence culture models at 20 and $44 \mathrm{~h}$ PI. The Figure depicts the confocal microscopy immunofluorescent images of HtrA (A-C, G-I) and MOMP (D-E, J-L) during different culture conditions of Chlamydia trachomatis L2, including; acute, penicillin persistence and IFN- $\gamma$ persistence. Scale bars $(10 \mu \mathrm{M})$ are shown in the bottom right of each figure.

et al., 2007), or finally due to different copy number requirements for the two genes. However, regardless of the minor differences in complementation by growth curve, it is clear that Chlamydia htrA can protect E. coli htrAagainst the detrimental affects of heat stress. This data pro- vides direct evidence for in vivo physiological functionality of C. trachomatis HtrA as a molecular chaperone and/or protease to protect against protein stress induced by high temperatures. The lack of a genetic manipulation system for Chlamydia limits the ability to collect in vivo physiolog- 
Table I: Quantification of HtrA immunofluorescence (as a ratio of LPS) during penicillin and IFN- $\gamma$ medicated persistence compared to untreated (acute) controls

\begin{tabular}{|c|c|c|c|}
\hline Acute & Penicillin & Acute & IFN- $\gamma$ \\
\hline 20 h PI & & 20 h PI & \\
\hline I.Ia $(0.08 b)$ & $0.84(0.089)$ & $0.74 \&(0.09)$ & $0.62(0.05)$ \\
\hline 44 h PI & & 44 h PI & \\
\hline $1.49(0.23)$ & $1.85(0.052)$ & $1.06(0.04)$ & $0.33(0.13)$ \\
\hline
\end{tabular}

a Each number represents the ratio of HtrA to LPS immunofluorescence in $>10$ individual inclusions dual labelled with LPS (FITC) and HtrA (56I) antibodies. Quantification of total fluorescence was conducted under identical laser and microscopy settings on slides prepared on the same day (acute and persistence model).

b Standard error measurements are shown in brackets beside each Figure.

\&Immunofluorescence for IFN- $\gamma$ cultures was conducted with a higher laser power setting for laser $56 \mathrm{I}$ collections to enable accurate calculations of the HtrA measurements. Due to this difference control acute ratios are shown for both conditions.

ical evidence, however we feel the use of this heterologous system has provided strong evidence that Chlamydia HtrA protects against protein stress in vivo.

Protein levels were examined in C. trachomatis L2 cultures under acute and heat stressed conditions to examine the role of the HtrA. Heat stress is an ideal laboratory model to induce protein level stress and is highly relevant for many bacteria, but it is important to note that $C$. trachomatis would more commonly encounter other forms of protein damaging stress such as, immune related oxidative and nitrosative stress, temperature flux in the genital tract, rapid $\mathrm{pH}$ changes during early development of the inclusion vacuole, and possibly osmotic flux. The increased level of HtrA during heat stress was observed both by western blot and immunofluorescence (relative to MOMP and LPS). The use of the major outer membrane protein (MOMP) as a comparative protein for molecular studies in Chlamydia is widely reported. MOMP levels have been reported to decrease during $C$. trachomatis persistence and stress conditions $[15,18]$. However, as different fixatives were required for the HtrA and MOMP antibodies used during this study, LPS was used in conjunction with HtrA immunofluorescence. The heat stress model we tested was consistent with previous studies on C. pneumoniae and $C$. trachomatis with both morphological similarity when examined by TEM and similar decreased levels of MOMP and LPS $[14,16,17]$. Furthermore, we tested under conditions for which it is known a high proportion of the C. trachomatis cells remain viable. That is, after 3 hrs heat shock at $42^{\circ} \mathrm{C}$ once heat stress is removed, C. trachomatis was able to complete the developmental cycle, and form infectious EBs [31]. This suggests that CtHtrA is important during heat stress and could be one of the key factors for protection of cellular envelope proteins sufficiently to allow restoration of normal growth once heat stress is removed. The protection is likely to be mediated by both the protease and chaperone functions we previously reported during in vitro investigations of HtrA [8]. The data presented here clearly indicates a cell envelope or extracytoplasmic localisation of HtrA which seems likely to be periplasmic as indicated by in silico predictions. Further experimental data would be needed to confirm the exact location of HtrA (periplasmic, cytoplasmic membrane, outer membrane), however, regardless of the exact location it is clear that HtrA's protein maintenance function would still serve much of the extracytoplasmic proteome.

Two well established persistence models were used during this investigation to test for the potential significance of HtrA for persistent infections. The penicillin induced persistence model affects the development of Chlamydia by binding to three penicillin binding proteins halting binary fission and preventing later phases of the chlamydial developmental cycle (formation of EBs) $[17,32]$. This affect of penicillin on Chlamydia is somewhat paradoxical as there is no unequivocal evidence for the presence of peptidoglycan, although it is predicted that peptidoglycan synthesis functions in RBs during chlamydial cell division (reviewed [33]). Thus, in the presence of penicillin at $20 \mathrm{~h}$ $\mathrm{PI}$, the RBs will have no peptidoglycan (PG) or components thereof, and less MOMP and outer membrane cysteine rich proteins such as OmcB $[18,19]$ which normally contribute to the rigidity of the outer membrane by extensive disulfide crosslinking. The decreased outer membrane disulfide crosslinking and peptidoglycan likely results in reduced extracytoplasmic integrity, reduced protection from osmotic and redox stress for extracytoplasmic proteins due to these reduced physical and chemical barriers. Osmotic and redox stress is known to affect protein integrity [34]. Thus, HtrA may be present at increased levels during penicillin persistence to protect against this possible additional protein stress. These findings suggest that HtrA is less important for the initial adaptation to penicillin but rather functions during longer term persistence presumably via maintenance of extracytoplasmic proteins possibly required for ongoing viability or for the capability to return to normal development once the selective pressure is removed.

HtrA protein levels were reduced at both $20 \mathrm{~h} \mathrm{PI}$ and $44 \mathrm{~h}$ PI during IFN- $\gamma$ persistence, possibly indicating that extracytoplasmic protein stress is less important during this form of persistence until at least $44 \mathrm{~h}$ PI. IFN- $\gamma$ persistence for Chlamydia is effectively a form of amino acid deprivation stress, which results in a lack of binary fission and prevention of $\mathrm{RB}$ development to EBs. The amino acid deprivation is not likely to result in direct stress on exist- 


\section{Acute}

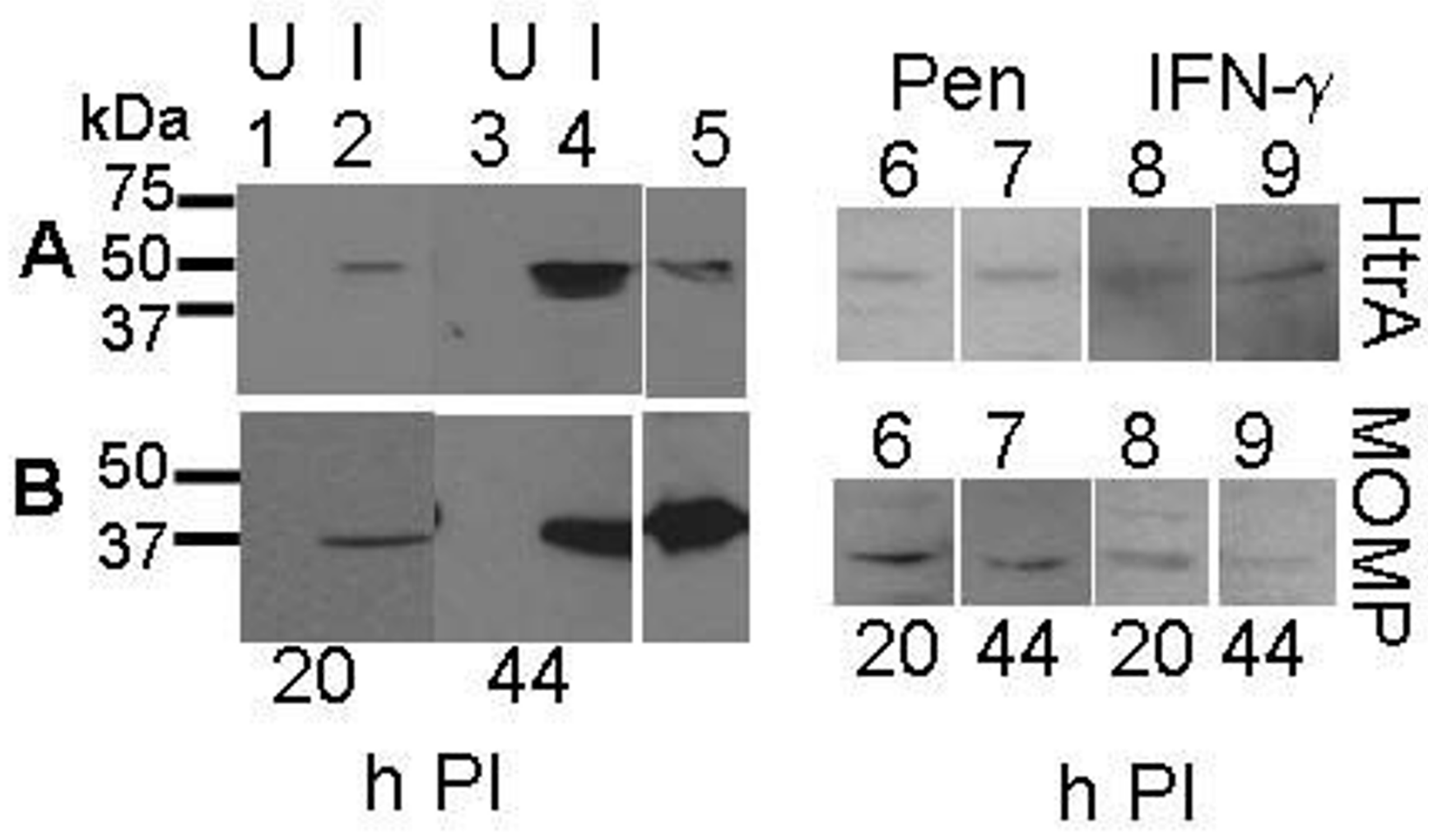

Figure 7

Western blots for HtrA and MOMP proteins during acute, IFN- $\gamma$ and persistence culture of $C$. trachomatis L2 to detect changes in protein levels. (A) HtrA, (B) MOMP. Samples on the western blots are: I. uninfected HEp-2 cell extract $(20 \mathrm{~h} \mathrm{PI}), 2$. C. trachomatis infected HEp-2 cell extract $(20 \mathrm{~h} \mathrm{Pl}), 3$. uninfected HEp-2 cell extract $(44 \mathrm{~h} \mathrm{PI}), 4$. C. trachomatis infected HEp-2 cell extract $(44 \mathrm{~h} \mathrm{PI})$, 5. purified recombinant HtrA/MOMP (A/B respectively), 6. (20 h PI) Penicillin persistence model, 7. (44 h PI) Penicillin persistence model, 8. (20 h PI) IFN- $\gamma$ persistence model, 9. (44 h PI) IFN- $\gamma$ persistence model. Lanes 6-9 are shown in reduced size.

ing extracytoplasmic proteins, which could explain the reduced levels of HtrA under these conditions. The considerable reduction in HtrA during IFN- $\gamma$ persistence, when compared to acute, heat stress and penicillin data, suggests that IFN- $\gamma$ persistence doesn't involve chlamydial extracytoplasmic stress response, unlike previous suggestions for C. pneumoniae that IFN- $\gamma$ persistence is a stress response [16].

\section{Conclusion}

The role of HtrA for Chlamydia likely involves both the protease and/or chaperone functions in protection, assembly, or degradation, of extracytoplasmic chlamydial proteins during intracellular development (RB), extracellular survival (EB), and stress conditions. The data presented here demonstrated the presence of HtrA during development, with increased HtrA levels during conditions which most likely induce protein stress, such as heat shock and penicillin induced persistence. Furthermore, the results suggest that IFN- $\gamma$ persistence doesn't involve an extracytoplasmic stress response for Chlamydia trachomatis. These observations combined with the demonstrated ability of Chlamydia HtrA to protect E. coli htrAagainst lethal heat stress in vivo, support an important role of HtrA for maintaining the viability of Chlamydia during any conditions where extracytoplasmic protein stability is compromised. The findings of this study have further contributed to the understanding of the role of HtrA for bacterial pathogenesis $[29,35]$, particularly within the intracellular niche.

\section{Methods}

Bacterial culture and media

E. coli were cultured using LB media [36] aerobically at $37^{\circ} \mathrm{C}$, aerobic broth cultures were shaken at $220 \mathrm{rpm}$. All cloning experiments and plasmid construction were con- 

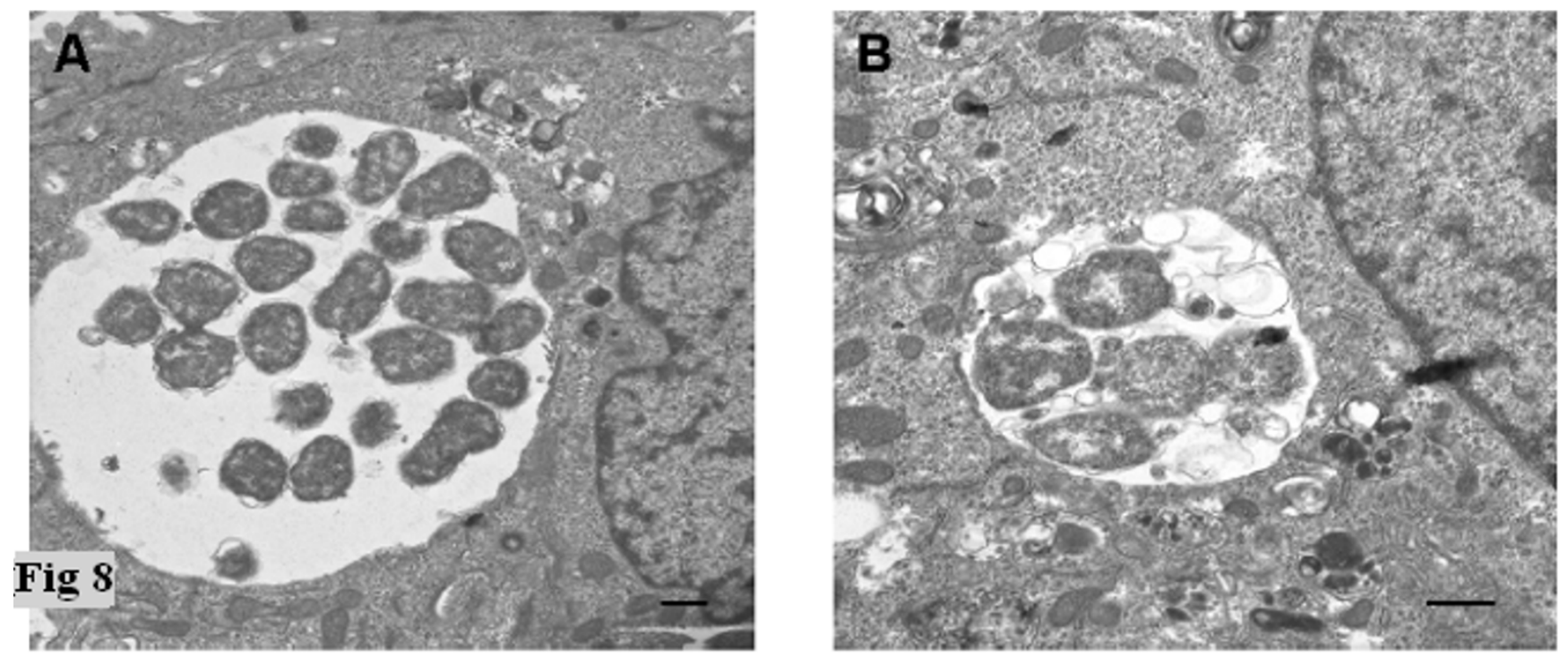

\section{Figure 8}

Transmission electron micrographs of $\boldsymbol{C}$. trachomatis infected HEp-2 cells. (A) The figure shows a $C$. trachomatis infected inclusion under acute conditions at $20 \mathrm{hrs}$ PI. (B) The figure shows a $C$. trachomatis infected inclusion within a HEp-2

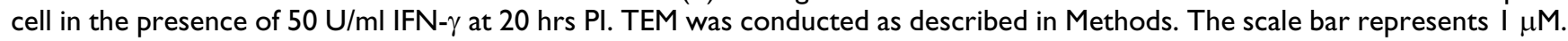

ducted and maintained in JM109. Genetic mutation and physiological experiments were conducted using E. coli MG1655. All chemicals were sourced from Sigma-Aldrich unless otherwise stated.

\section{Cell culture and Chlamydia culture}

The human epithelial cell line (HEp-2) were cultured in DMEM media supplemented with $5 \%$ fetal calf serum, 50 $\mu \mathrm{g} / \mathrm{ml}$ gentamycin, and $10 \mu \mathrm{g} / \mathrm{ml}$ streptomycin, at $37^{\circ} \mathrm{C}$ $5 \% \mathrm{CO}_{2}$. All C. trachomatis $\mathrm{L} 2$ infections were established at $70-90 \%$ infectivity and media was changed at $4 \mathrm{~h}$ post infection to media containing $1 \mu \mathrm{g} / \mathrm{ml}$ cyclohexamide. Heat stress experiments were performed in an incubator at $42{ }^{\circ} \mathrm{C}, 5 \% \mathrm{CO}_{2}$. Penicillin persistence was established by addition of penicillin at time of media change (150 mins $\mathrm{PI})$ to a final concentration of $50 \mathrm{U} / \mathrm{ml}$. IFN- $\gamma$ was added to the HEp- 2 cells $24 \mathrm{~h}$ prior to infections at $50 \mathrm{U} / \mathrm{ml}$ and maintained throughout the experiment with media changes every $24 \mathrm{~h}$.

\section{Genetic manipulations, PCRs and plasmid constructs}

E. coli MG1655 htrA-mutant was generated using the $\lambda$ red recombinase method essentially by the method described by Datensko and Wanner (2000). The pDK13 template plasmid (kanamycin resistance) was used with the primers EchtraF4 5'-ttgtaaagacgaacaataaatttttaccttttgcagaaacttta gttcgtcaaacatgagaattaattccgggg-3' and EchtraR4 5'-aagatgcc agccagccataagtcctccgttatgcacggcttagcataaggcatatgaatatcctccttag-3. The PCR product was used to electroporate MG1655 E. coli containing the $\lambda$ red recombinase expres- sion plasmid pKD46. Expression of the recombinase was induced with $10 \mathrm{mM}$ arabinose during culture of the cells for electrocompetency preparation. The E. coli htrA gene was mutated by insertion/deletion of the htrA open reading frame with the PCR product, regions of homology with the E. coli genome for the sites of recombination are shown underlined in the above primers. The mutation was confirmed using PCR analysis of purified genomic DNA using the primers K1 5'-tgcagttcattcagggcaccg-3', K2 5'-atgcccgacggcgaggatc-3', EcHtrAf5 5'-tgaccgacctctatgcgtgg-3' and EcHtraR5 5'-atggtacgtcggacgatatcc-3' to show insertion of the kanamycin resistance cassette into the genome in the place of the htrA gene.

The complementation plasmids were constructed using PCR products generated from purified genomic DNA isolated from E. coli MG1655 or C. trachomatis L2. pACYCechtrA was generated by PCR of the htrA gene from E. coli using the primers echtrAf6 5'-gcggatccatggccgtagaacaataacccagg-3' and echtraR6 5'-ccgcatgcataaggaagtacgtaacgtaccgg-3'. The E. coli htrA PCR product was cloned into the pACYC184 vector by double digest using the primer incorporated restriction endonuclease sites for BamH1 and Sph1 (underlined). A similar strategy was employed to generate the pACYCcthtrA complementation vector, whereby the PCR product was amplified using the primers cthtraF10 5'-ggggatccttggagaatcatcagagtag-3' and cthtraR2 5'-ttgcatgcctactcgtctgatttcaagacgatg-3'. The PCR product was cloned into pACYC184 using the restriction endonucleases BamH1 and Sph1, primer incorporated 


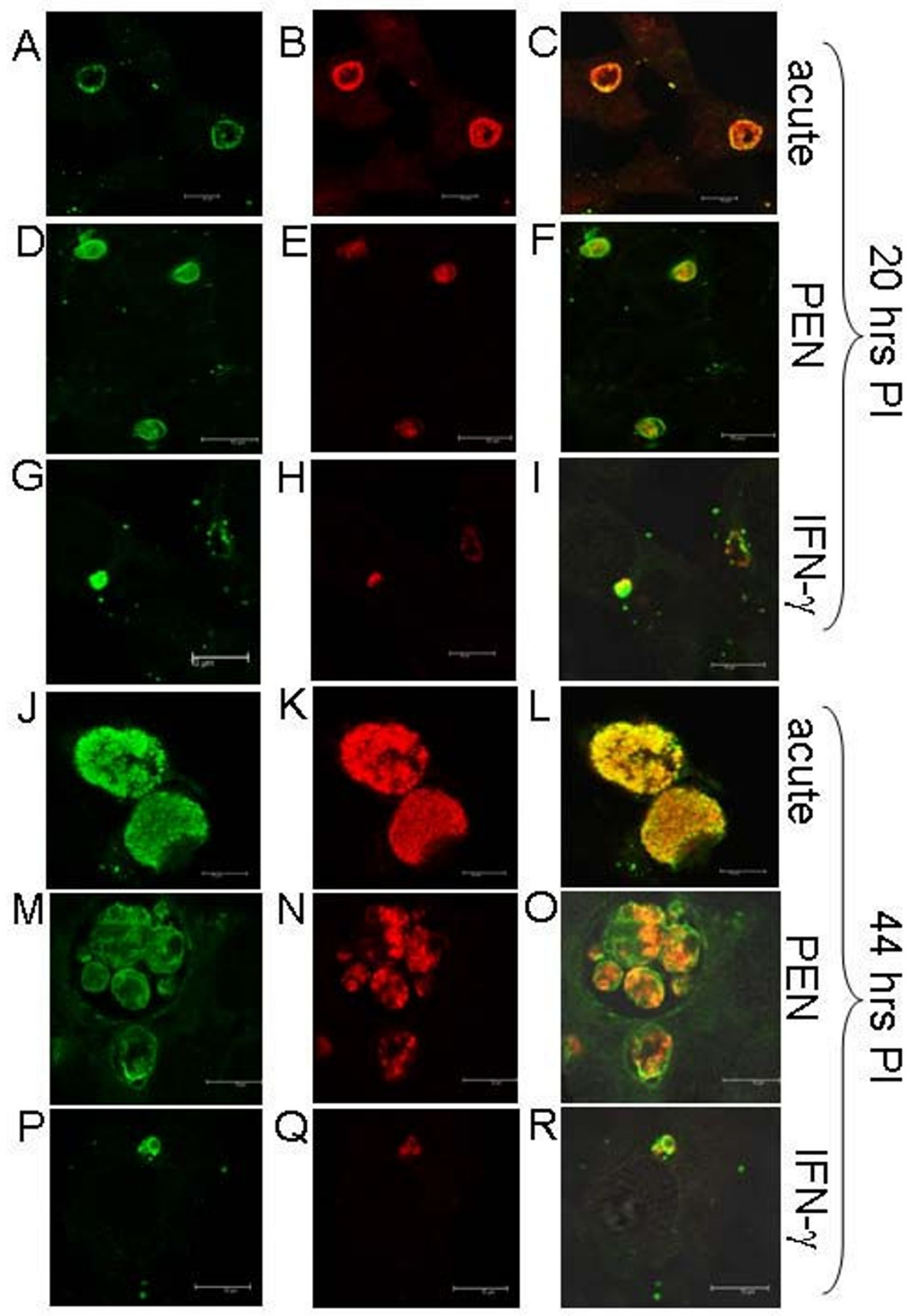

Figure 9

Confocal microscopy images of dual labelled immunofluorescence of HtrA and LPS during C. trachomatis L2 HEp-2 cultures. The figure shows immunocytochemistry of acute, penicillin persistent, and IFN- $\gamma$ persistent cultures fixed and stained with HtrA and LPS antibodies at $20 \mathrm{~h}$ and $44 \mathrm{~h}$ post infection. The LPS antibody (shown in green, column I) has a FITC label directly conjugated to the antibody, the HtrA antibody (shown in red, second column) was detected using a secondary antiRabbit IgG antibody with an Alexa Fluor label (56I). Overlays are shown in the third column. Scale bars (I0 $\mu M)$ are shown in the bottom right of each figure. 
sites (underlined). All PCR reactions were conducted using Pfu DNA polymerase (Promega, Australia) as per the manufacturer's instructions. Plasmid constructs were confirmed by restriction enzyme digest and sequence analysis on both strands prior to transformation into $E$. coli MG1655 and E. coli htrA- using electroporation.

\section{Bioinformatic analysis of protein sequences}

Bioinformatic analysis was conducted using the following programs; EclustlW [37], key residues were identified by alignment with E. coli HtrA using MULTALIN [38], PDZ domains predicted by MOTIFSCAN [39], prediction of subcellular localisation was conducted using the program PSORT [25].

\section{Generation of polyclonal sera}

Polyclonal sera against recombinant purified HtrA [8] was commercially generated by IMVS (South Australia). Rabbits were injected with $200 \mu \mathrm{g}$ of purified HtrA protein in Freunds complete adjuvant, with a further three boosts using $200 \mu \mathrm{g}$ purified HtrA protein in Freunds incomplete adjuvant.

\section{Western blots and preparation of protein extracts}

E. coli total extracts were prepared by harvesting cells by centrifugation at $4000 \times \mathrm{g}$ for $10 \mathrm{mins}$. Cells were washed and resuspended in PBS ( 0.1 volume), and lysed by sonication (Misonix 3000) and total protein concentration determined using the BCA assay (Sigma-Aldrich, Australia). Total extract from HEp-2 cell cultures (infected and uninfected) were harvested from monolayers conducted in tissue culture flasks. Media was removed and cells washed in cold PBS. Cells were scraped into a small volume of PBS ( 0.05 original media volume, identical volumes used for acute and test conditions) and lysed by sonication prior to quantification of total protein extract. Polyacrylamide gel electrophoresis (PAGE) was conducted to test protein harvests and for western blots. Samples were loaded to identical protein concentrations from total protein extracts for western blot analysis. Western transfers were conducted using Hybond-C (GE Healthcare, Australia). Western blots to analyse E. coli extracts were blocked in $0.5 \%$ skim milk powder in TBS, HtrA polyclonal sera was used as primary antibody at 1/7000 dilution (0.5\% skim milk powder, TBS). Anti-rabbit HRP conjugate antibody (Sigma-Aldrich) was used as the secondary antibody $(1 / 10000)$ and ECL Plus Western Blotting Detection System (GE Healthcare, Australia) was used for detection. Western blot analysis of Chlamydia cell culture extracts were conducted using the same procedure, although $0.5 \% \mathrm{w} / \mathrm{v}$ casein (Roche, Australia) was used as the blocking agent and the HtrA polyclonal sera was used as primary antibody at $1 / 200$ dilution and the MOMP monoclonal antibody was used at $1 / 1000$. HRP conjugated secondary antibodies were used at 1/10000 dilution
(Sigma-Aldrich, Australia). Recombinant MOMP was generated as described by Barker and coworkers [40].

\section{Transmission electron microscopy and immunofluorescence}

Transmission electron microscopy was conducted on samples which were cultured concurrent to the experiments analysed by western blot. The cultures were fixed in $3 \%$ glutaraldehyde (ProSciTech), $0.1 \mathrm{M}$ cacodylate buffer, $\mathrm{pH}$ 7.3. After overnight fixative cells were scraped and washed in $0.1 \mathrm{M}$ cacodylate buffer. Cells were postfixed in $1 \%$ osmium tetroxide and embedded in Spurr expoy resin. Ultrathin sections $(50-100 \mathrm{~nm})$ were cut and stained with uranyl acetate and lead citrate stains prior to examination and photography using the JEOL 1200EX transmission electron microscope.

Immunocytochemistry samples were prepared using cells cultured on coverslips. Coverslips were washed in PBS prior to fixative for 15 mins $(100 \%$ methanol for HtrA and LPS, 4\% paraformaldehyde, PBS for MOMP). Cells were permeabilised by incubation in $0.5 \% \mathrm{v} / \mathrm{v}$ triton $\mathrm{X}$ 100 , PBS for 15 mins prior to blocking in $1 \% \mathrm{w} / \mathrm{v}$ BSA for 20 mins. $0.1 \%$ BSA was used for LPS antibody staining and no permeabilisation step was used. Primary antibody was incubated for 1 hour in 1\% BSA (LPS no dilution, HtrA $1 / 500$ sera dilution, MOMP $1 / 1000$ dilution). MOMP monoclonal antibody (MOMP mAb) was sourced from Biodesign International (C955135), LPS-FITC conjugated antibody was sourced from Cellabs, Australia. Washes were conducted using $0.2 \%$ Tween-20 PBS or PBS when the LPS antibody was used. Secondary antibodies were used at $1 / 600$ dilution in $1 \%$ BSA for 1 hour. Secondary antibodies used were Alexa Fluor 488 goat anti-mouse and Alexa Fluor 488 goat anti-rabbit (Invitrogen, USA). Co-labelling with LPS and HtrA was conducted in 0.05\% BSA, washed in PBS, and the HtrA antibody was detected using a secondary anti-rabbit IgG Alexa Fluor 568. Coverslips were mounted using Prolong Gold antifade (Invitrogen, USA) and viewed under a Leica TCS SP5 confocal laser scanning microscope (Leica Microsystems) with a 63 $\times$ oil objective 1.4 NA. Images were captured using the Leica application suite for advanced fluorescence. No immunofluorescence was detected in samples stained with either primary or secondary antibody alone. Quantification was conducted on the same day, to compare samples which were previously prepared (triplicate experiments; cultures, and slide preparations for direct comparisons were also conducted at the same time). Quantification of fluorescence was calculated using the Leica application suite.

\section{Authors' contributions}

WMH conducted the experiments, microscopy experiments were conducted in conjunction with CT. WMH, 
SAM, and PT designed and conceived the study. WMH wrote the manuscript. All authors analysed results, read, and approved the manuscript.

\section{Additional material}

\section{Additional file 1}

Video of series of Z-sections collected during immunocytochemistry of C. trachomatis L2 infected HEp-2 cell stained with HtrA polyclonal sera at $20 \mathrm{~h}$ PI (Alexa Fluor 488). The video demonstrates the staining of HtrA was around the edge of each RB within this inclusion. The staining around the periphery of each $R B$ was consistently observed at this time point indicating a likely periplasmic location of HtrA. Scale bar $10 \mu \mathrm{M}$. Click here for file

[http://www.biomedcentral.com/content/supplementary/14712180-8-190-S1.zip]

\section{Acknowledgements}

W.M.H is supported by a NHMRC Peter Doherty Postdoctoral Fellowship. The authors wish to thank $\mathrm{Dr}$ Chris Barker for supplying purified recombinant MOMP used in the western blots. The authors thank Dr Leo De Boer and Steven Bell for technical assistance, and Dr Paul Burrell for proofreading the manuscript.

\section{References}

I. Clausen T, Southan C, Ehrmann M: The HtrA family of proteases: Implications for protein composition and cell fate. Mol Cell 2002, I 0(3):443-455.

2. Lipinska B, Fayet O, Baird L, Georgopoulos C: Identification, characterization, and mapping of the Escherichia coli htrA gene, whose product is essential for bacterial growth only at elevated temperatures. J Bacteriol 1989, 171:1574-1584.

3. Stauch KL, Beckwith J: An Escherichia coli mutation preventing degradation of abnormal periplasmic proteins. P Natl Acad Sci USA 1998, 85:1576-1580.

4. Kim KI, Park SC, Kang SH, Cheong GW, Chung CH: Selective degradation of unfolded proteins by the self-compartmentalizing HtrA protease, a periplasmic heat shock protein in Escherichia coli. J Mol Biol 1999, 294(5): |363-1374.

5. Spiess C, Beil A, Ehrmann M: A temperature-dependent switch from chaperone to protease in a widely conserved heat shock protein. Cell 1999, 97(3):339-347.

6. Skorko-Glonek J, Zurawa D, Kuczwara E, Wozniak M, Wypych Z, Lipinska B: The Escherichia coli heat shock protease HtrA participates in defense against oxidative stress. Mol Gen Genet 1999, 262(2):342-350.

7. Rowley G, Spector M, Kormanec J, Roberts M: Pushing the envelope: extracytoplasmic stress responses in bacterial pathogens. Nature Reviews Microbiology 2006, 4:383-394.

8. Huston WM, Swedberg JE, Harris JM, Walsh TP, Mathews SA, Timms $P:$ The temperature activated HtrA protease from pathogen Chlamydia trachomatis acts as both a chaperone and protease at $37^{\circ} \mathrm{C}$. Febs Lett 2007, 581:3382-3386.

9. Abelrahman YM, Belland RJ: The chlamydial developmental cycle. FEMS Microbiology Review 2005, 29:949-959.

10. Belland RJ, Zhong G, Crane DD, Hogan D, Sturdevant D, Sharma J, Beatty WL, Caldwell HD: Genomic transcriptional profiling of the develomental cycle of Chlamydia trachomatis. P Natl Acad Sci USA 2003, 100:8478-8483.

II. Hogan R, Mathews SA, Mukhopadhyay S, Summersgill JT, Timms P: Chlamydial persistence: beyond the biphasic paradigm. Infect Immun 2004, 72: I843-I855.

12. Beatty WL, Belanger TA, Desai AA, Morrison RP, Byrne GI: Tryptophan depletion as a mechanism of gamma interferonmediated chlamydial persistence. Infect Immun 1994, 62:3705-37II.
13. Beatty WL, Byrne Gl, Morrison RP: Morphologic and antigenic characterization of interferon $\gamma$-mediated persistent Chlamydia trachomatis infection in vitro. P Natl Acad Sci USA 1993, 90:3998-4002.

14. Beatty WL, Morrison RP, Byrne GI: Immunoelectron-microscopic quantification of differential levels of chlamydial proteins in a cell culture model of persistent Chlamydia trachomatis infection. Infect Immun 1994, 62:4059-4062.

15. Belland RJ, Nelson DE, Virok D, Crane DD, Hogan D, Sturdevant D, Beatty WL, Caldwell HD: Transcriptome analysis of chlamydial growth during IFN- $\gamma$-mediated persistence and reactivation. P Natl Acad Sci USA 2003, 100:1597|-15976.

16. Mukhopadhyay S, Miller RD, Sullivan ED, Theodoropoulos C, Mathews SA, Timms P, Summersgill JT: Protein expression profiles of Chlamydia pneumoniae in models of persistence versus those of heat shock response. Infect Immun 2006, 74:3853-3863.

17. Kramer MJ, Gordon FB: Ultrastructural analysis of the effects of penicillin and chlortetracycline on the development of a genital tract Chlamydia. Infect Immun 197I, 3:333-34I.

18. Gerard HC, Kraube-Opatz B, Wang Z, Rudy D, Rao PJ, Zeidler H, Schumacher HR, Whittum-Hudson JA, Kohler L, Hudson AP: Expression of Chlamydia trachomatis genes encoding products required for DNA synthesis and cell division during active versus persistent infection. Mol Microbiol 200I, 4I:73I-74I.

19. Lambden PR, Pickett MA, Clarke IN: The effect of penicillin on Chlamydia trachomatis DNA replication. Microbiology 2006, I 52:2573-2578.

20. Skorko-Glonek J, Wawrzynow A, Krzewski K, Kurpierz K, Lipinska B: Site-directed mutagenesis of the HtrA (DegP) serine-protease, whose proteolytic activity is indispensable for Escherichia coli survival at elevated-temperatures. Gene 1995 163(I):47-52

21. Kim DY, Kim KK: Structure and function of HtrA family proteins, the key players in protein quality control. J Biochem $\mathrm{Mol}$ Biol 2005, 38(3):266-274.

22. Krojer T, Garrido-Franco M, Huber R, Ehrmann M, Clausen T: Crystal structure of DegP (HtrA) reveals a new protease-chaperone machine (vol 4l6, pg 455, 2002). Nature 2002, 417(6884): 102-102.

23. Kay BB, Kehoe JW: PDZ domains and their ligands. Chemistry and Biology 2004, I I:423-425.

24. Iwanczyk J, Damjanovic D, Kooistra J, Leong V, Jomaa A, Ghirlando R, Ortega J: Role of the PDZ domains in Escherichia coli DegP protein. J Bacteriol 2007, I 89(8):3|76-3|86.

25. Gardy JL, Laird MR, Chen F, Rey s, Walsh CJ, Ester M, Brinkman FSL: PSORTb v.2.0: Expanded prediction of bacterial protein subcellular localization and insights gained from comparative proteome analysis. Bioinformatics 2005, 21 :617-623.

26. Bendtsen JD, Nielsen H, von Heijne G, Brunak S: Improved prediction of signal peptides: SignalP 3.0. J Mol Biol 2004, 340:783-795.

27. Datsenko KA, Wanner BL: One-step inactivation of chromosomal genes in Escherichia coli K-1 2 using PCR products. $P$ Natl Acad Sci USA 2000, 97:6640-6645.

28. Leonhardt RM, Lee SJ, Kavathas PB, Cresswell P: Severe tryptophan starvation blocks oncet of conventional persistence and reduces reactivation of Chlamydia trachomatis. Infect Immun 2007, 75:5105-5II7.

29. Pedersen LL, Radulic M, Doric M, Abu Kwaik Y: HtrA homologue of Legionella pneumophila: an indispensable element for intracellular infection of mammalian but not protozoan cells. Infect Immun 200I, 69(4):2569-2579.

30. Johnson K, Charles I, Dougan G, Pickard D, O'Gaora P, Costa G, Ali T, Miller I, Hormaeche C: The role of a stress-response protein in Salmonella typhimurium virulence. Mol Microbiol 1991, 5:401-407.

3I. Kahane S, Friedman MG: Reversibility fo heat shock in Chlamydia trachomatis. Fems Microbiol Lett 1992, 97:25-30.

32. Barbour AG, Amano K, Hackstadt T, Perry L, Caldwell HD: Chlamydia trachomatis has penicillin-binding proteins but not detectable muramic acid. J Bacteriol 1982, I5 I:420-428.

33. McCoy AJ, Maurelli AT: Building the invisible wall: updating the chlamdyial peptidoglycan anomaly. TRENDS in Microbiology 2006, I 4:70-76.

34. Miot M, Betton JM: Protein quality control in the bacterial periplasm. Microbial Cell Factories 2004, 3:. 
35. Chatfield SN, Strahan K, Pickard D, Charles I, Hormaeche I, Dougan G: Evalutation of Salmonella typhimurium strains harbouring defined mutations in htrA and aroA in the murine salmoneallosis model. Microb Pathogenesis |992, I 2: |45-|5|.

36. Sambrook J, Fritsch EF, Maniatis T: Molecular Cloning: A laboratory Manual. New York: Cold Spring Harbour; 1989.

37. Thompson JD, Higgins DG, Gibson TJ: CLUSTAL W: improving the sensitivity of progressive multiple sequence alignment through sequence weighting, positions-specific gap penalties and weight matrix choice. Nucleic Acids Research 1994, 22:4673-4680.

38. Corpet $\mathrm{F}$ : Multiple sequence alignment with hierarchical clustering. Nucleic Acids Research 1988, 16:1088I-10890.

39. Falquet L, Pagni M, Bucher P, Hulo N, Sigrist CJ, Hofmann K, Bairoch A: The PROSITE database, its status in 2002. Nucleic Acids Research 2002, 30:235-238.

40. Barker CJ, Beagley KW, Hafner LM, Timms P: In silico identification and in vivo analysis of a novel T-cell antigen from Chlamydia, NrdB. Vaccine 2008, 26: 1285-1296.

Publish with Bio Med Central and every scientist can read your work free of charge

"BioMed Central will be the most significant development for disseminating the results of biomedical research in our lifetime. "

Sir Paul Nurse, Cancer Research UK

Your research papers will be:

- available free of charge to the entire biomedical community

- peer reviewed and published immediately upon acceptance

- cited in PubMed and archived on PubMed Central

- yours - you keep the copyright 